\title{
Longing for Sustainability- A General View of Western Market
}

\author{
Md. Sanuwar Rashid \\ Assistant Professor, Textile Engineering Department \\ Daffodil International University \\ 102, Sukrabad, Mirpur Road, Dhaka-1207, Bangladesh \\ Tel: 88-01-729-634-269 E-mail: Sanuwar_69@yahoo.com
}

Received: December 10, 2010

Accepted: January 5, 2011

doi:10.5539/jsd.v4n2p40

\begin{abstract}
The aim of this paper is to focus on the transformation of consumer conception which causes market volatility and inflation of product in market. As the competition among the marketers to offer the new product in market is stiffer than ever, costing of marketing is gradually increasing. On the other hand, consumers want to have the product as per their wish. It does mean that the western market is totally unstable and sustainable issues prioritize for the future betterment. This article struggles to figure out the recent challenges of unstable market and focus on relevant literature to aware the consumer on sustainable issue. This article digs deeper to denote the findings based on problem discussion and relevant literature has been brought out to give us the insight of sustainable issue in western market.
\end{abstract}

Keywords: Western market, Market volatility, Sustainability, Meaningful responsiveness 1. Introduction

From the very beginning of human creation, we have been continuously striving for excellence. It is our inherent desire to make our life more stable than the existing situation. And the natural phenomenon of this desire was modernism. Modernism had come when we touched the milestone of minimum stability. And from the early modernism to post modernity, we have dominated on everything as per our wish. In the mean time, we have observed the revolution of globalization and information technology (Lyotard, 1979). As everything has been done through globalization and IT, what is waiting for us in near future? May be the past history is going to return back with a decorative patchwork (Simonetta, 2009)! Our attitudes were converted with the pace of time from 'form follows function' to 'form follows fiction'. Now it is time to incline us towards the trend 'form follows meaning' as we longing for sustainability (Simonetta, Votava, 2009).

\section{Problem discussion}

Today's western market is volatile than ever. The traditional thinking of inventory making and waiting for customer demand is now less and less viable for the company. Now the level of uncertainty is greater; the risk is lot higher. Most markets have become a lot more turbulent, the sort of spikes in demand that many companies experience whether it is in consumer products or fashion product is getting harder each day. The technological improvement and the most changing fashion trend reduce the product life cycle (Ericsson, 2003). So market is now unstable.

Moreover, dogma of always new insist marketer to bring new product. We wonder if it's possible to draw too many new product to market because at the end, consumer find everything same as previous. Does it mean that everybody is coping from everyone! The figure no. 1 shows that the perplexing situation is getting worse in the era of excellence.

I have found a statistical data regarding the inflation of product having same end use objectives (Saguy \& Moskowitz 1999); The U.S. launch about 20,000 new products annually although perhaps 1100 to 1200 products are counted as real news. 33\% of product innovations are assessed as successful, $25 \%$ are deemed unsuccessful which are rapidly disappeared from market and the rest $42 \%$ of product follows the declining sales figures. Still now there is no significant standard to measure how successful the newly launched product is. But consumer and consumer's satisfaction should be the focus of each part of business, in every aspect of product development and product launch process.

Another perplexing condition regarding market situation is like that it is moved into hyper saturated status from saturation. Marketing cost is increasing day by day due to excessive advertisement, logistics support and e-logistic setup in business process. But still now sales is not significantly gear up which is better shown in figure no. 2. And if we could not able to boost up the sales in a significant level then market will be collapsed (Simonetta, 2009)! 
So, it is urgent to think about today's marketing diversity against consumer value before it's too late. While we have heard that consumer wallet can change the world, there our findings are: 'market volatility', 'everybody is coping' \& 'market is going to collapse'!

And the fate of eastern people is not well enough to think or experience the above problem like shop bulimia or shop anorexia. It is really hard to believe that when the western people are thinking about the tale of modernity, a huge percentage of eastern people are fighting for their basic needs. Though the eastern part isn't the real focus of this paper, but is it possible for western part to sustain along by discarding the eastern part? Western people are heavily dependent on eastern part for outsourcing of products. As it is earlier mentioned that marketing cost is increasing day by day, it will create a huge pressure on them if they want to avoid this outsourcing. So the thought of market collision is going to be more imminent.

So have a very short over view about the developing part of the world. This part is struggling for their existence, still now. They have lot of problems like flood, erosion, salinity increment, rise of sea water level which are the general symptoms of global warming. I have no intention to make a debate on who is responsible for this disruption. But western part should come forward to tackle this situation because no single part of world can exist alone.

\section{Literature review}

In this part, I have a wish to focus on pure theoretical background of sustainability to make us understand about its implementation in daily practice.

\subsection{Sustainability:}

It is the reconciliation of environmental, social and economic demand. How perfectly we can sustain in this planet is depends on the uniform synchronization of these three factors. That's why these are known as three pillar of sustainability. The figure no. 3 represents a true relation of these 3 factors with sustainability.

\subsection{Sustainable business:}

So far I found, Sustainable business is the best way to keep the world sustainable as it has no negative impact on the global and local environment, community, society and economy. For example, Patagonia, people's tree are doing their business in the same way and they are very successful as they take any business decision by considering sustainability, even they only do work with eco-friendly product from raw material to finished goods and overall they have a enduring commitment on the environment. Sustainable business, therefore strives to meet the triple bottom line (Cooney, S. 2009).

\subsection{Triple bottom line:}

Triple bottom line refers as the people, planet and profit which combine with each other to measure the values and criteria for organizational success (Elkington 1994).

3.3.1 People (Human Capital): To be sustainable in business, company should merge itself with a social structure where people are considered as stakeholder and the relation of people and company should be interdependent through the society.

3.3.2 Planet (Natural capital): To avoid the negative impact on environment, company should do life cycle assessment of product which gives them an idea about the environmental cost of harvesting and growth of raw materials and the eventual disposal by the end user. And if the product is not degradable or toxic, then company should bear the responsibility of its disposal cost.

3.3.3 Profit: Profit is the ultimate goal for every organization whether it does sustainable business or not. But the organization, which thinks about sustainability, should consider itself as a stakeholder as same of people and planet rather than share holder.

\subsection{Sustainable development:}

'Sustainable development' referred as the relation between environmental, social and economical aspects which are known as the "three pillars" of sustainability. Sustainable development is subjected for making a balance between the natural resources and standard life improvement of human being as well as preserving them for the future. Sustainable development deals with those factors which are directly or indirectly effect to our daily life, natural issues and environmental aspects. It is a continual development process and mainly oriented with our global economics, natural issues and human life (Figure 4). Therefore, it is inherent that everybody should participate on the sustainable development process. 


\subsection{Three layers of sustainability:}

I already have defined the term sustainability in many aspects. But whatever we intend to do for sustainability, we should have a define format to keep us on the right track. And there is no standard measure of predefined action while cultural influence is the main theme. On the basis of cultural value, we have to have vision and belief which will be strongly backed up by standards and code of conduct. Then a perfect accumulation of individual responsibility and transparency can truly incline us towards the goal of sustainability. The figure no. 5 expresses the matter in a better way.

\section{Findings}

In problem discussion, There were a discussion of problem regarding marker volatility', 'everybody is coping' \& the increment of marketing cost where sale in gradually decreasing. So now it's time to think what we have done and what we're continuously doing. We have to understand that, with the pace of time to keep us updated, we consume environmental asset as our own wish. In this paradigm, our moral value, respect to other is in oscillation. We, therefore, at first need to change our point of view and then materialize our value (Simonetta \& Votava, 2009). We should go for authenticity, real quality \& real price, transparency, integrity, originality, simplicity and over all normality to achieve meaningfulness responsibility. And this responsibilities as a human being can provide us a long term sustainability. We are now 7.0 billion people in the world. And we are consuming something for meeting our needs and wants at every day. Have we ever thought that how much capacity our planet has to absorb our left over? Moreover, some product having polyethylene, polyester needs 700 years to start decomposition! So what we think, isn't the artificial product are direct threat to our planet? In problem discussion we've found that over the years, how our needs (basic needs) are transformed into dream and causes an over saturated status of market through hyper segmentation. And the subsequent impact was higher marketing cost while sales figures are gradually plummeting for the inflation of product. Just as a tremendous heat and pressure create a diamond, we still have a chance to deploy our sense and moral values to create a sustainable market. The figure no. 6 illustrates the possible shift of paradigm by our latent sense and personal value which are inclining towards the sustainable market as well as sustainable business.

Therefore, we have to emphasize more on meaningfulness responsibility while the advancement of technologies will be devoted for waste management strategy and industrial ecology.

\subsection{Waste management strategies:}

This strategy cover the collection, transport, processing, recycling or disposal and monitoring of waste materials to reduce their effect on health, environment and aesthetics. The main purpose of waste management is to recover resources from it. Even the new waste management strategy places more emphasize on waste recycling and recovery through a mixture of approaches including the renewal of recycling targets, focused awareness campaigns and the possible introduction of incentive schemes (Rogers, March 2006).

\subsection{Industrial ecology (IE):}

Emergent behavior of complex integrated human/natural systems is the main focus of Industrial Ecology (Allenby, Brad 2006). It combines the environment, economy and technology in an effective way to make the overall sociology sustainable. The emission of gas from different industry like CFC is responsible for the ozone's hole, water pollution, air pollution. And the crisis is nowadays deep enough to think about industrial ecology.

\subsection{Meaningfulness responsibility:}

As a consumer we need to develop our meaningfulness responsibility in taking the decision of our consumption. Dogma of always new insist us to lead our life as an individual person and encourage us to expose ourselves with the attitude of domination. But as a human being, we should have ethics. And if we consider ethical point of view then we can learn about our responsibility to this planet. If we really want to be happy then we should belong to transparency, integrity, originality as well as simplicity and normality. Every society is identified for their cultural value and we should develop our vision \& belief, responsibility \& transparency, and standard \& code of conduct which persist our cultural value to be sustainable (Simonetta 2009). So authenticity is going to be our next frontier to keep our planet well enough not only for us but also for our next generation. Authenticity is something more than sincerity, honesty, truth, beauty; actually it is that what it is! So we should be authentic enough to develop our meaningfulness responsibility to make marketer understand that we are now thinking for long term survival issue.

The grounded theory may be recalled in here while we are in confusion to estimate our attitude regarding responsiveness. According to this model theory, we can calibrate our points of view regarding any initiative 
whether it is related with any kind of strategy having socio-cultural impact or the initiative is solely based on personal opinion. By performing continuous review of observable facts, we can induce any initiative as per our personal interpretation. The induction methodology will come into action through concepts, indicators and categories of that initiative while the initiative is related directly with market sustainability or some other issues like: waste management strategies and industrial ecology which are the very basic steps inclining toward market sustainability. Therefore, the ultimate outcome represents the facts and findings of that particular initiative (Figure 7).

\section{Conclusion}

In the section 'problem discussion' I have focused on some critical problem and in 'finding' section I have written my idea on behalf of this problem. There, I have emphasized more on personal point of view rather than the role of marketer. Because whatever we are doing and what we are deciding affect our earth. In problem discussion, I've also talked about the developing part of world but in literature review and in finding section, you won't find about this part. It may be the limitation of my report but I do strongly believe that in near future the western part collaborate with eastern part to make the planet sustainable.

\section{References}

Allenby, Brad. (2006). The ontologies of industrial ecology, Progress in Industrial Ecology (Inderscience Enterprises Ltd.) 3 (1/2): 28-40.

Bauman, Zygmunt. (2009). Liquid Times: Living in an Age of Uncertainty. Polity, Print.

Clarke, A. (2005). Situational Analysis: Grounded Theory After the Postmodern Turn. Thousand Oaks, CA: Sage Publications.

Cooney, S. (2009). Build A Green Small Business, Profitable ways to become an ecopreneure.

Elkington, J. (1994). Towards the sustainable corporation: Win-win-win business strategies for sustainable development. California Management Review 36, no. 2: 90-100

Ericsson, D. (2003). Supply and Demand Chain Management: The next frontier for competitiveness. Global Logistics Waters, D. (ed)

Jean-François Lyotard. (1979). The Postmodern Condition publ. Manchester University Press, 1984.

Lecture of Simonetta Carbonaro, Design of prosperity seminar. (2009). http://thedesignofprosperity.se/2009/press/carbonaro/CTF_09_The_function_of_fashion.pdf

Lecture of Yvon Chouinard, Design of prosperity seminar. (2009). http://thedesignofprosperity.se/2009/press/chouinard/TheNext100Years-YvonChouinard-Patagonia-Inc.pdf

Munasinghe, M. (2007). The sustainable Triangle, The encyclopedia of earth.

Rogers. (March 2006). Towards Resource Management: The Northern Ireland Waste Management Strategy $2006-2020$.

Saguy I. S. \& Moskowitz H. R. (Aug 1999). Integrating the Consumer into New Product Development. Food technology, Vol 53, part 8, pg. 68-72.

Simonetta Carbonaro, Christian Votava. (2009). The function of fashion? The desing of new styles... of thoughts; Textile Journal, page- 31-45. 


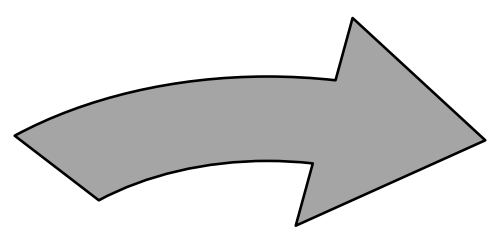

Dogma of the always new

\section{More of the-Difference \\ Yet- the-same}
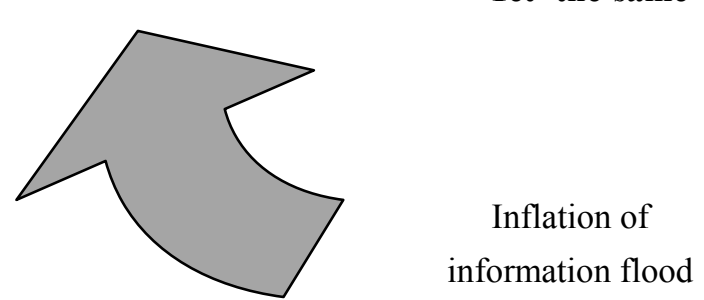

Inflation of Product

Development

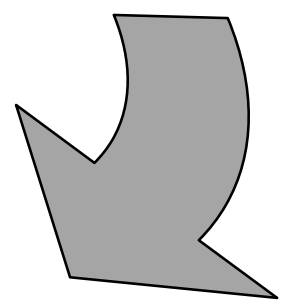

Figure 1. Dogma of new insist of lunching new product in Market though all is same (Simonetta, 2009)
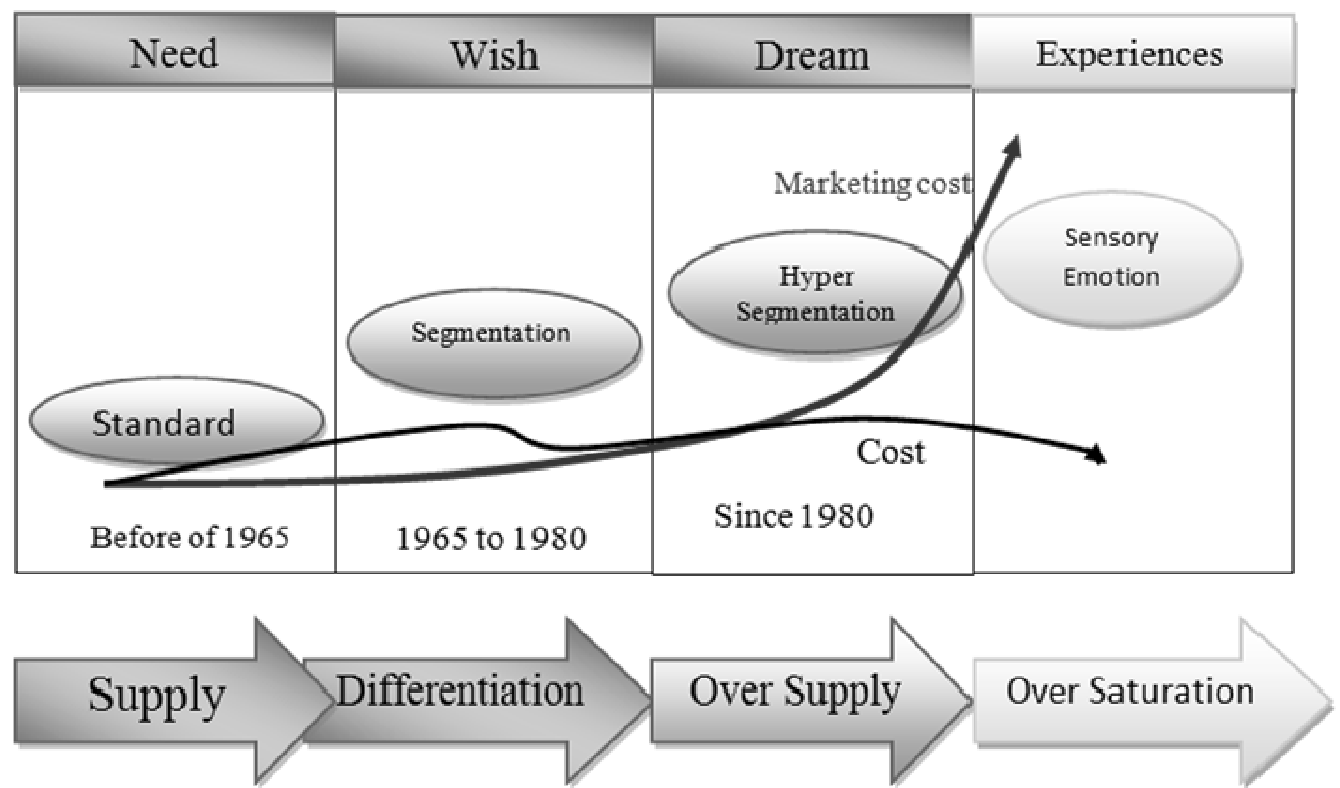

Figure 2. A diagram of chronological development of marketplace accelerated by consumer's need to experiences (Bauman, Zygmunt 2009) 


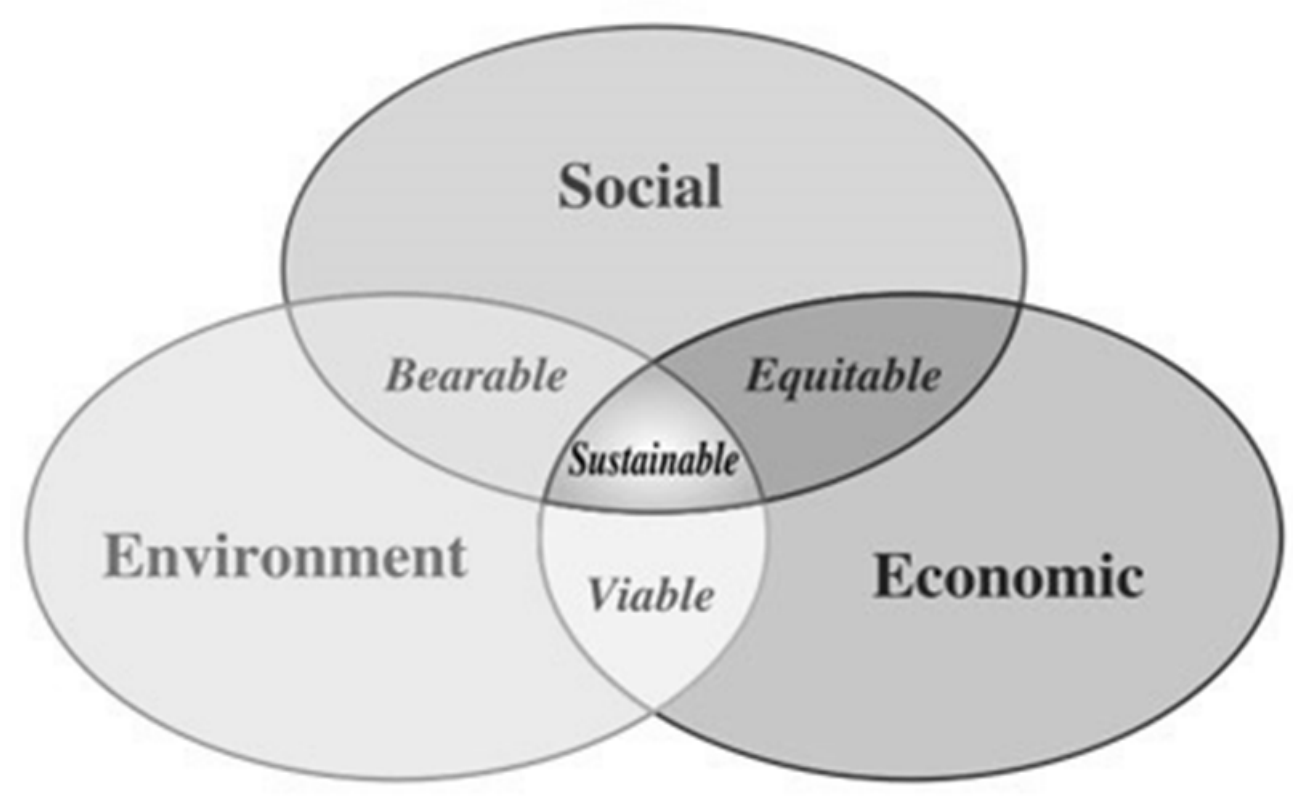

Figure 3. interrelation of these three factors with sustainability (Adams, W.M. 2006)

- growth

- efficiency

- stability

Economic

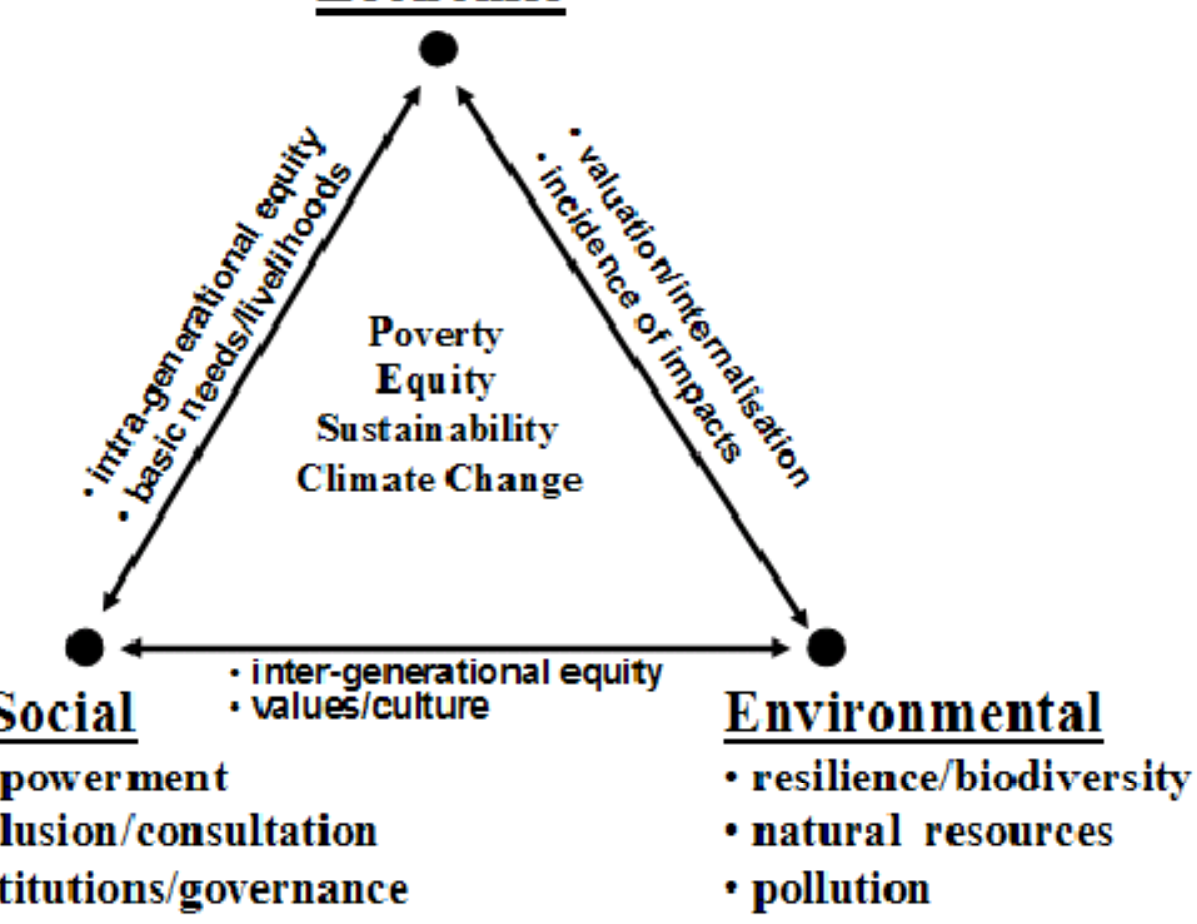

Figure 4. Sustainable development triangle (Munasinghe, M 2007) 


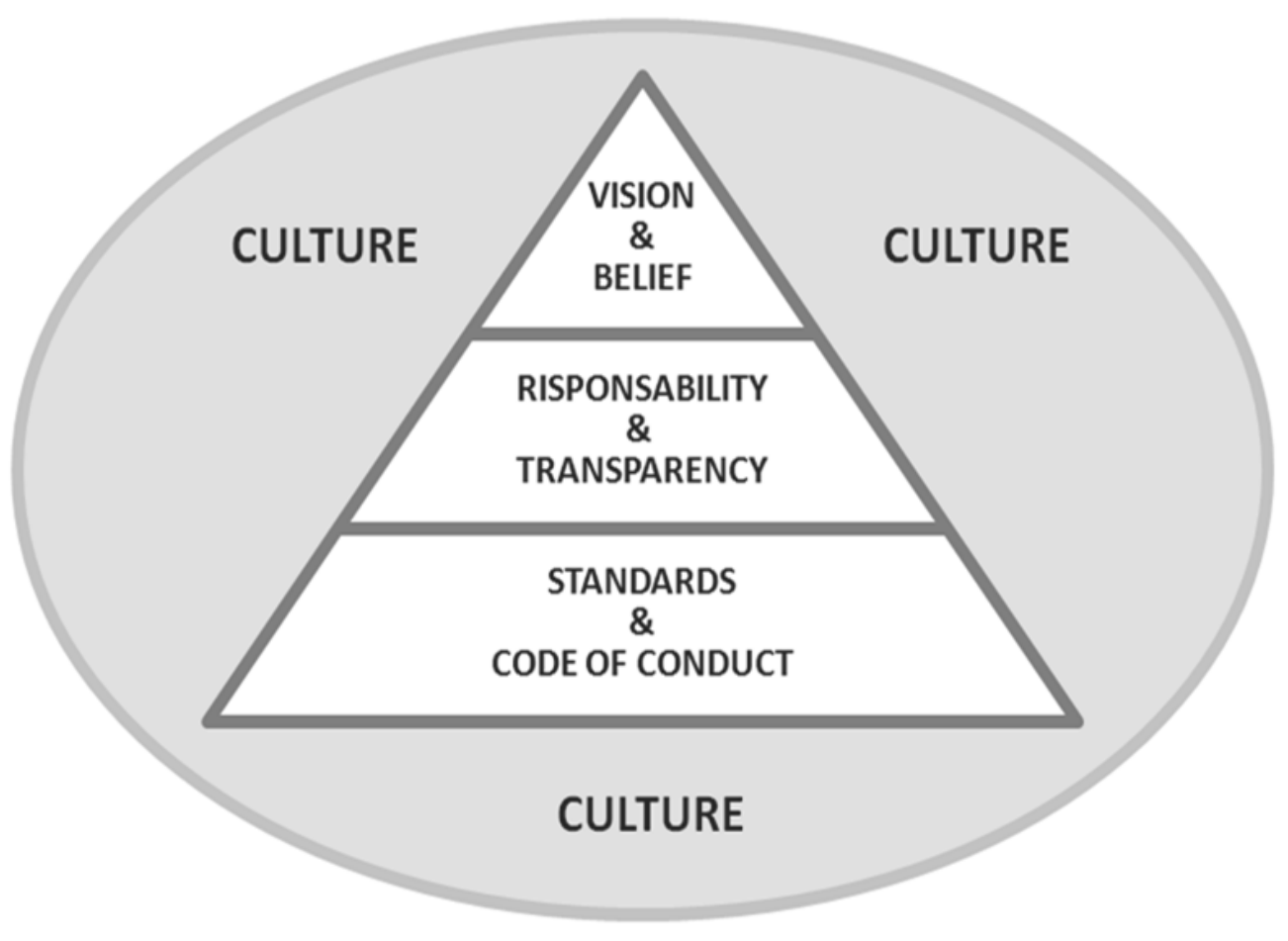

Figure 5. Three layers of sustainability (Simonetta, Votava 2009)

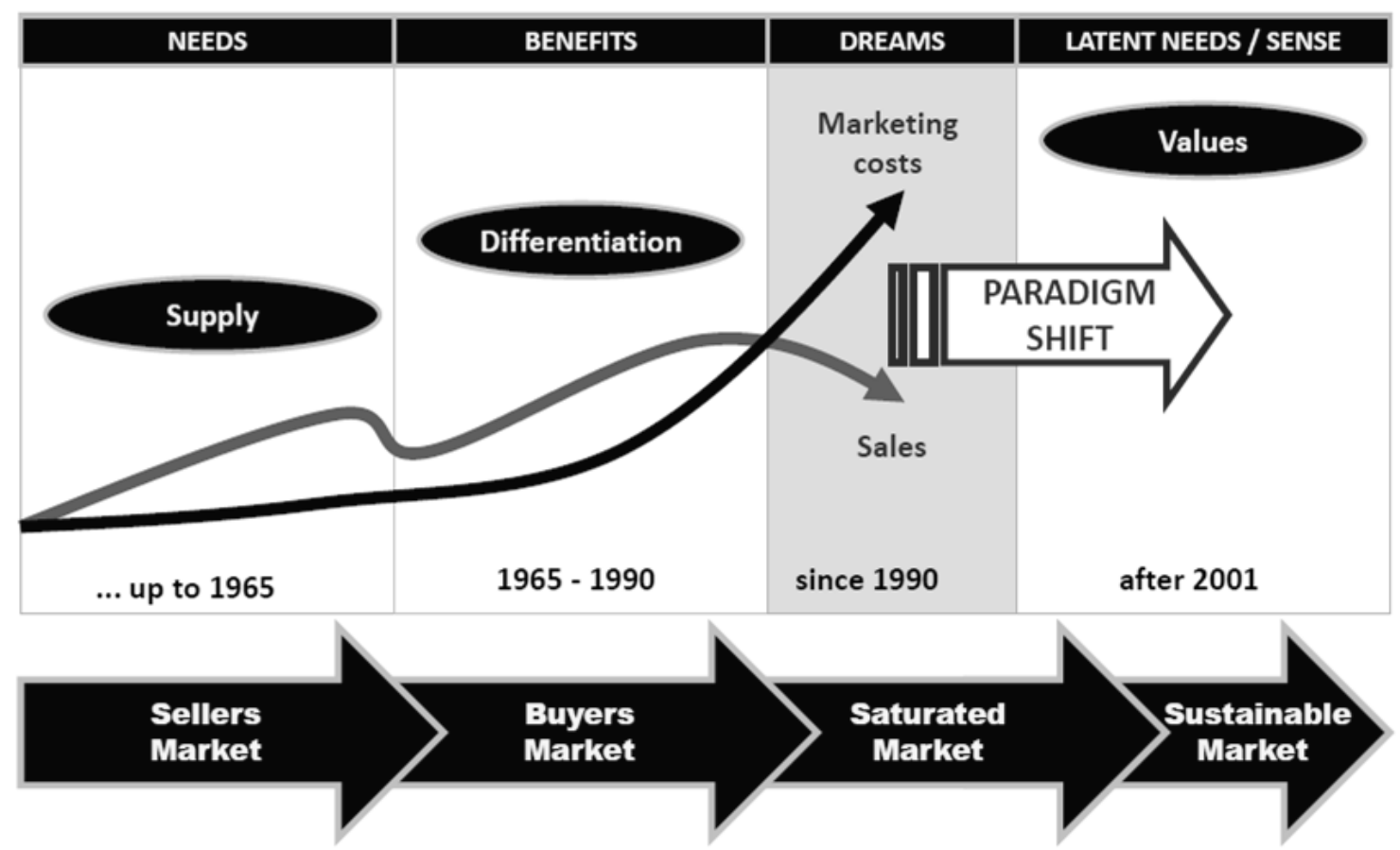

Figure 6. A new era of sustainable market is getting started form saturated market by deploying latent needs and meaningful value of individual (Hypothesis by Author) 


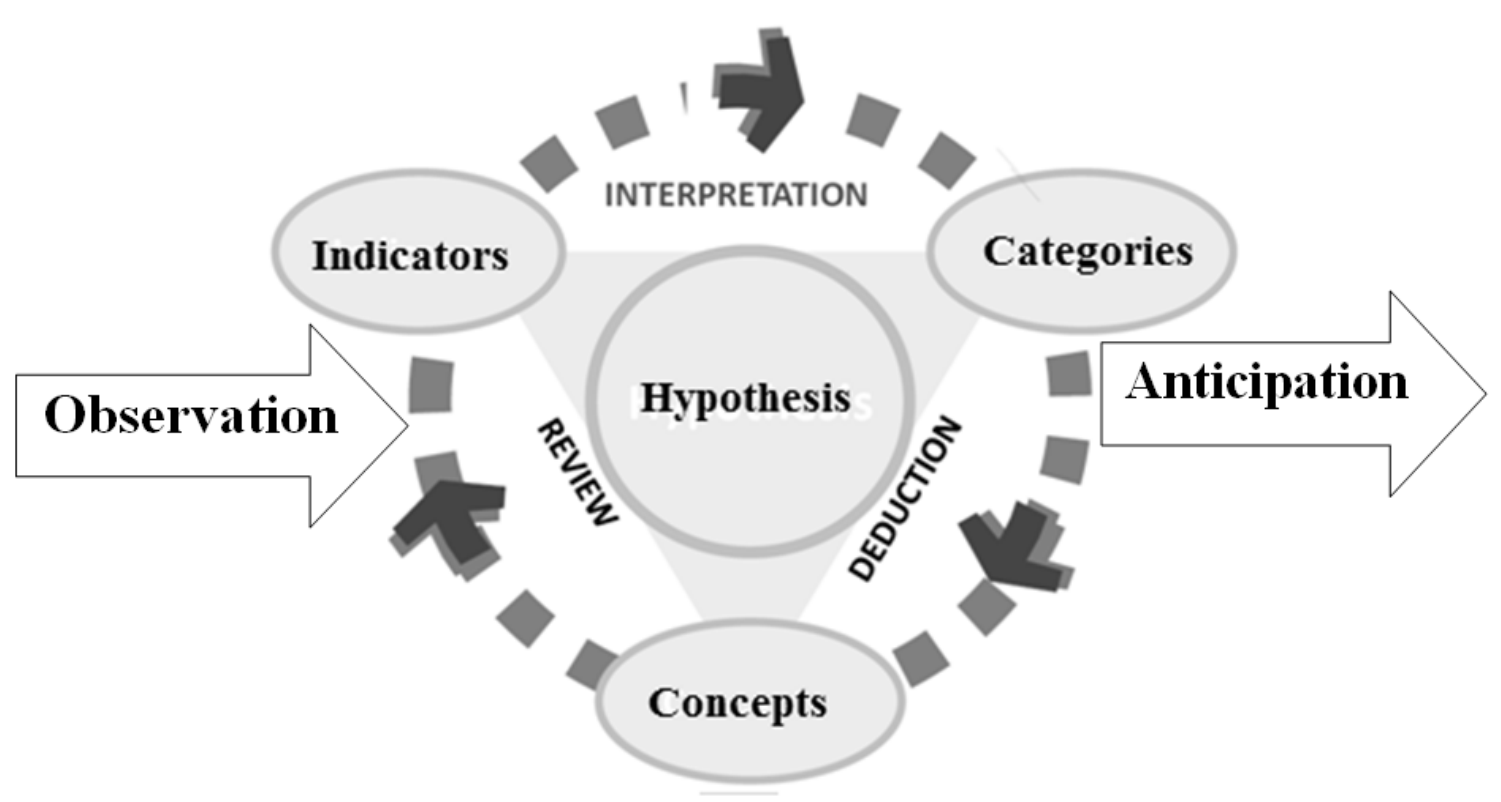

Figure 7. The Grounded Theory for reviewing our initiatives regarding long term sustainability (Clarke, A 2005) 